\title{
18 $\alpha$-glycyrrhetinic acid targets prostate cancer cells by down-regulating inflammation-related genes
}

\author{
ADITYA V. SHETTY ${ }^{1 *}$, SIVASAKTHIVEL THIRUGNANAM ${ }^{1 *}$, GAJALAKSHMI DAKSHINAMOORTHY $^{1}$, \\ ABHILASH SAMYKUTTY ${ }^{1}$, GUOXING ZHENG ${ }^{1}$, AOSHUANG CHEN ${ }^{1}$, MAARTEN C. BOSLAND $^{2}$, \\ ANDRÉ KAJDACSY-BALLA $^{2}$ and MUNIRATHINAM GNANASEKAR ${ }^{1}$ \\ ${ }^{1}$ Department of Biomedical Sciences, University of Illinois, College of Medicine, Rockford, \\ IL 61107; ${ }^{2}$ Department of Pathology, University of Illinois, Chicago, IL 60612, USA
}

Received March 16, 2011; Accepted April 26, 2011

DOI: $10.3892 /$ ijo.2011.1061

\begin{abstract}
Glycyrrhetinic acid is an active triterpenoid metabolite of glycyrrhizin abundantly present in licorice roots. Glycyrrhetinic acid exists as $\alpha$ and $\beta$ stereo-isomeric forms. Both stereo-isomeric forms are known to have anti-inflammatory and anticancer activity. However, the effects and anticancer mechanism of $\alpha$ glycyrrhetinic acid in prostate cancer cells has not yet been evaluated. Therefore, we investigated the growth inhibition, induction of apoptosis and the anticancer mechanisms of $18 \alpha$-glycyrrhetinic acid (AGA), on the androgen-independent metastatic prostate cancer cell line DU-145. Our results showed that AGA inhibited proliferation and growth of these cells by inducing apoptosis as determined by Annexin V and flow cytometry analyses. Our studies also showed that HUVEC tube formation was drastically reduced when cultured in conditioned medium of AGA-treated DU-145 cells. In addition, AGA treatment prevented the invasion of DU-145 prostate cancer cells on matrigel coated transwells via down-regulation of NF- $\mathrm{B}$ (p65), VEGF and MMP-9 expression. Furthermore, AGA treatment also downregulated the expression of pro-inflammatory cytokine/growth factor genes HMGB1, IL-6 and IL-8 in DU-145 cells. Interestingly, AGA simultaneously upregulated the expression of non-steroidal anti-inflammatory gene-1 (NAG-1) in DU-145 cells suggesting its anti-inflammatory activity on prostate cancer cells. Taken together, the results of this study suggest that AGA may be a promising anticancer agent that merits further investigation for the chemoprevention and treatment of prostate cancer.
\end{abstract}

Correspondence to: Dr Munirathinam Gnanasekar, Department of Biomedical Sciences, University of Illinois, College of Medicine, 1601 Parkview Ave., Rockford, IL 61107, USA

E-mail:mgnanas@uic.edu

*Contributed equally

Key words: $18 \alpha$-glycyrrhetinic acid, DU145, inflammation, invasion and prostate cancer

\section{Introduction}

Prostate cancer is the most frequently diagnosed non-cutaneous malignancy and the second leading cancer-related cause of death in men, responsible for nearly 30,000 deaths per year in the United States (1). It was estimated that prostate cancer would be responsible for $28 \%(186,320)$ of all newly diagnosed cancers by 2010 . Primary stages of the disease can be treated with surgery, androgen ablation and or radiation therapy. Patients undergoing hormonal therapy eventually develop aggressive hormone unresponsive disease. Hence, the major focus in prostate cancer research is the discovery of better chemotherapeutic agents for the advanced hormone-resistant, metastatic form of this disease.

Licorice root extract, obtained from Glycyrrhiza glabra, is a well known oriental herbal medicine that has been most frequently prescribed for the treatment of various diseases. Chinese medicinal practitioners recommend licorice root for its life-enhancing properties and cure of injury or swelling and for detoxification $(2,3)$. It is also used as a flavoring and sweetening agent in drug preparations, tobacco, chewing gums, candies and beverages (4-6). The major active component of licorice root is glycyrrhizin, an oleanane-type triterpene saponin which constitutes $2-24 \%$ of total dry weight (7). Glycyrrhizin is extensively reported to have several pharmacological activities including anti-inflammatory (8), immunomodulatory (9), antiulcer (10) and anti-tumorigenic activities $(11,12)$. Glycyrrhizin also has antiviral activity against hepatitis B virus, HIV $(13,14)$ and severe acute respiratory syndrome (SARS)-associated coronavirus (15).

When orally administered, before absorption, human intestinal bacteria completely convert glycyrrhizin to its aglycone metabolite glycyrrhetinic acid (16), which exhibits higher bioactivity than its precursor (17). Like glycyrrhizin, glycyrrhetinic acid can exist as two stereoisomers, the trans form $18 \alpha$-glycyrrhetinic acid (AGA) and the cis form $18 \beta$-glycyrrhetinic acid (BGA) $(18,19)$. Major structural differences between $18 \alpha$ - and $18 \beta$-glycyrrhetinic acids lie in the spatial orientation of hydrogen atom of $\mathrm{C} 18$, in BGA hydrogen atom of $\mathrm{C} 18$ and the carboxyl of C30 are in the same plane while in AGA, they are not in same plane (20). BGA has been more extensively studied because of its abundance in root extract. Though it was widely believed 
that BGA has high bioactivity, some studies showed that AGA has comparable bioactivity to BGA $(21,22)$. In vivo studies using mouse model demonstrated that AGA has more effective anti-inflammatory potential than BGA $(22,23)$. AGA is found to be very effective in inhibiting skin tumor initiation and promotion (24). In this study, we have investigated the anticancer activity and mechanisms of AGA using DU-145 prostate cancer cells.

\section{Materials and methods}

Chemicals and reagents. Fetal calf serum (FCS), RPMI-1640 and minimum essential medium (MEM) were obtained from American Type Cell Culture (ATCC, Manasas, VA). 18 $\alpha$-glycyrrhetinic acid (AGA) was purchased from Sigma-Aldrich (St. Louis, MO). Cell viability assay kit was purchased from Dojindo Molecular Technologies Inc., (Gaithersberg, MD). Annexin $\mathrm{V}$-FITC apoptosis detection Kit was obtained from MBL International (Woburn, MA).

Cell lines and cell culture. LNCaP, DU-145 and HUVEC cell lines were obtained from ATCC. LNCaP and DU-145 cells were cultured in RPMI medium supplemented with $10 \%$ FCS and $50 \mu \mathrm{g} / \mathrm{ml}$ gentamycin. HUVEC were cultured in EBM-2 medium (Lonza Walkersville Inc., MD) supplemented with $10 \%$ fetal bovine serum (FBS), hydrocortisone, basic human fibroblast growth factor (hFGF-b), vascular endothelial growth factor (VEGF), insulin-like growth factor (R3-IGF-1), ascorbic acid and human epidermal growth factor (hEGF). For tube formation assay, HUCEC were grown in conditioned medium of DU-145 cells. For all experiments, $1 \times 10^{5}$ cells $/ \mathrm{ml}$ were seeded and grown for $24 \mathrm{~h}$ before experimental treatments. Cells were maintained at $37^{\circ} \mathrm{C}, 5 \% \mathrm{CO}_{2}$ environment.

Cell viability assay. LNCaP and DU-145 cells were treated for different periods of time with different doses of AGA. Cell viability was measured using a CCK- 8 kit purchased from Dojindo Molecular Technologies Inc. Briefly, cells were cultured in 96-well plates in the presence of $10 \mu \mathrm{l}$ aliquots of AGA at various concentrations ranging from 10 to $500 \mu \mathrm{M}$. Following exposure to AGA, $10 \mu 1$ of CCK-8 solution was added to each well, and the plates were incubated for $3 \mathrm{~h}$ at $37^{\circ} \mathrm{C}$ and read immediately at $450 \mathrm{~nm}$ using a microplate reader (Bio-Rad, Richmond, CA).

Assessment of apoptosis in DU-145 cells by fluorescent microscopy and flow cytometry. DU-145 cells were stained with an Annexin V-FITC apoptosis detection kit (MBL) to determine whether cells are undergoing apoptosis. Propidium iodide staining was used as a control to differentiate cells undergoing necrosis. DU-145 cells were seeded in tissue culture slides and allowed to attach for $24 \mathrm{~h}$. After treating with AGA for $48 \mathrm{~h}$, cells were resuspended in $500 \mu \mathrm{l}$ of $1 \mathrm{X}$ binding buffer, $5 \mu 1$ Annexin V-FITC and $5 \mu 1$ of propidium iodide were added and incubated for $5 \mathrm{~min}$ at $37^{\circ} \mathrm{C}$ in the dark. The number of viable and apoptotic cells were analyzed by fluorescent microscopy. Flow cytometry analysis was also performed as described previously $(25,26)$ to evaluate the effects of AGA on DU-145 cells. DU-145 cells were treated with $100 \mu \mathrm{M}$ AGA for $48 \mathrm{~h}$, washed with PBS, fixed in ice cold $70 \%$ ethanol and

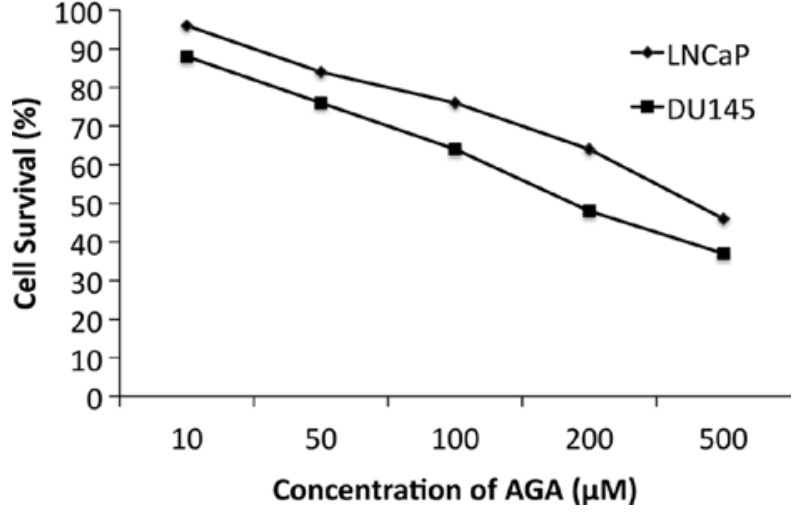

Figure 1. Dose-dependent cytotoxic effects of AGA in LNCaP and DU-145 cells. Cells were grown in 96-well plates for $24 \mathrm{~h}$ and were then exposed to AGA at serial concentrations for $48 \mathrm{~h}$. Following incubation, viability of cells was determined by MTT assay. Results show that AGA significantly decreased the viability of both LNCaP and DU-145 cells. Data are representative of one of five similar experiments.

stained with propidium iodide. Stained cells were then subjected to flow cytometry (BD FacsCalibur).

Tube formation assay. HUVEC tube formation assay was performed as reported previously (27) with some modifications. Briefly, HUVEC cells were cultured in a conditioned medium obtained from untreated DU-145 cells or DU-145 cells treated with AGA in a 96-well tissue culture plate coated with matrigel (BD Biosciences, San Jose, CA) for $24 \mathrm{~h}$ at $37^{\circ} \mathrm{C}$ in a $5 \% \mathrm{CO}_{2}$ atmosphere.

Matrigel invasion assay. In vitro invasion of DU-145 cells was carried out as described previously (28) with minor modification. In brief, DU-145 cells $\left(1 \times 10^{6}\right)$ plated on matrigel-coated transwell inserts (BD Biosciences) were left untreated or treated with $100 \mu \mathrm{M}$ AGA for $24 \mathrm{~h}$. Cells which invaded through the matrigel coated inserts were stained with HEMA stain, counted and photographed under a light microscope.

Western blot analysis. DU-145 cells treated with $100 \mu \mathrm{M}$ AGA for $24 \mathrm{~h}$ were lysed with sample solubilizing buffer and subjected to SDS-PAGE, transferred to nitrocellulose membrane and probed with anti-p65 (MBL international Inc.), anti-MMP-9 (Cell Signaling Technologies), anti-VEGF (Fisher Scientific) or anti $\beta$-actin antibodies (Sigma-Aldrich). Untreated cells served as controls.

Real-time quantification of cytokine genes. Quantification of gene expression of HMGB1, IL-6, IL-8 and NAG-1 was determined using real-time PCR technique. For gene expression studies, DU-145 cells were incubated for $48 \mathrm{~h}$ in presence of $100 \mu \mathrm{M}$ AGA. Following treatment, the cells were lysed with TRIzol reagent and the RNA extracted. Untreated cells served as controls. From the RNA samples, cDNA was synthesized using SA Biosciences PCR kit. A SYBR green based gene specific real-time PCR quantification kit (SA Biosciences) was used to analyze the expression of HMGB1, IL-6, IL-8 and non-steroidal anti-inflammatory gene-1 (NAG-1) genes. Real-time amplification of genes was performed in Applied Biosystems 7300 real-time PCR instrument. 
Control

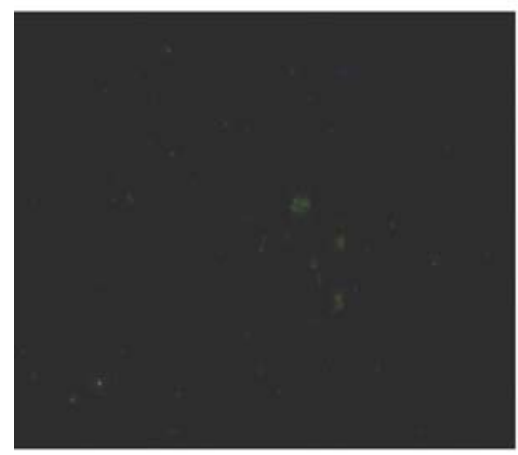

$100 \mu \mathrm{M}$ AGA

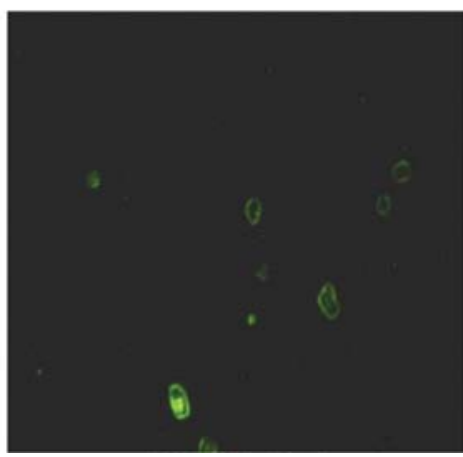

$200 \mu M$ AGA

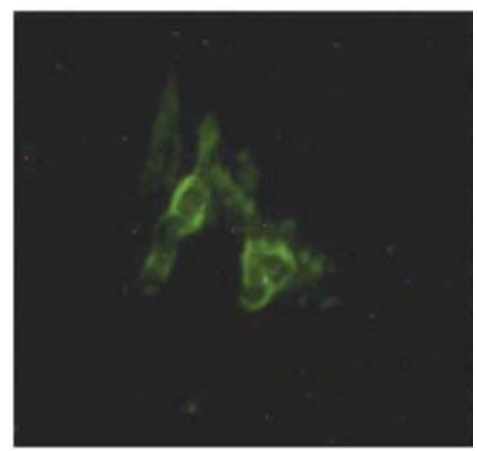

Figure 2. Annexin V-FITC detection of apoptosis in prostate cancer cells: DU-145 cells ( $10^{4}$ cells/ml) cultured in tissue culture slides were treated with AGA for $48 \mathrm{~h}$. Untreated cells incubated in DMSO alone served as control. Following treatment, cells were stained with Annexin V-FITC and propidium iodide. The cells were visualized under a fluorescence microscope. Results show that prostate cancer cells treated with AGA undergo apoptosis in a dose-dependent manner compared to control cells.
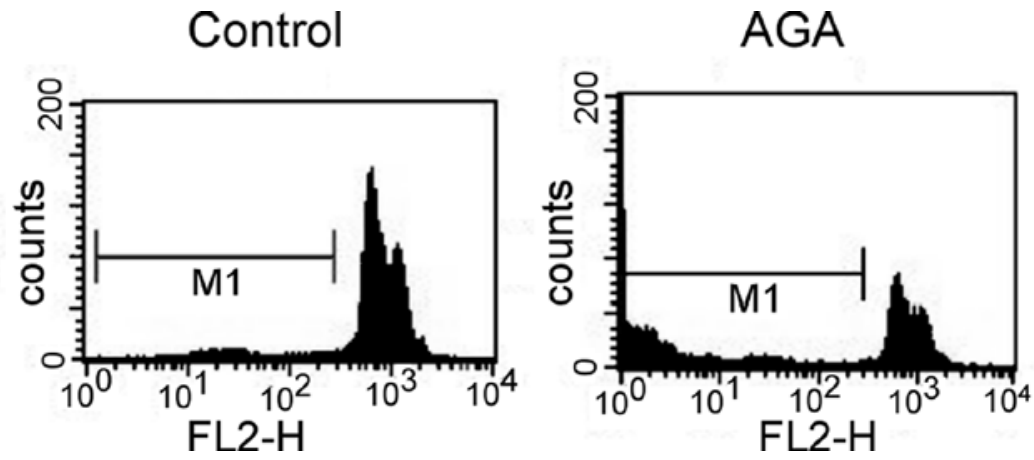

Figure 3. AGA induces cell death in DU-145 prostate cancer cells. DU-145 cells treated with $100 \mu \mathrm{M}$ AGA for $48 \mathrm{~h}$ were stained with PI and subjected to flow cytotmetry analysis. Results showed that $34 \%$ of DU-145 cells were dead (M1) while only $3 \%$ of cells were dead in the control DU-145 group. Results are representative of one of three similar experiments.

Statistical analyses. Data were compared using Mann-Whitney rank sum test using SigmaStat program (Jandel Scientific, San Rafel, CA). $\mathrm{P}<0.05$ was considered statistically significant.

\section{Results}

AGA inhibited growth and proliferation of DU-145 cells in a dose-dependent manner. LNCaP and DU-145 cells were treated with varying concentrations of AGA for $48 \mathrm{~h}$. Cell viability assay revealed that AGA treatment induced a dose-dependent reduction in cell viability starting at $100 \mu \mathrm{M}$ concentrations on both androgen-dependent $\mathrm{LNCaP}$ and androgen independent prostate DU-145 cancer cells (Fig. 1). Interestingly, DU-145 cells were more sensitive to AGA treatment and hence further characterization studies were focused on DU-145 cells.

AGA induces apoptosis in DU-145 cells. To further characterize the effects of AGA on DU-145, Annexin V-FITC and propidium iodide staining was used to determine the cause of cell death. DU-145 cells were treated with 100 or $200 \mu \mathrm{M}$ AGA for $48 \mathrm{~h}$ and stained with Annexin V-FITC and propidium iodide to visualize the cells under fluorescent microscope. Fluorescent microscopic analysis demonstrated that DU-145 cells treated with AGA were undergoing apoptosis and positively correlated with dose of AGA exposure (Fig. 2).
Similarly, flow cytometry analyses also confirmed that AGA treatment induced apoptosis in DU-145 cells (Fig. 3)

AGA inhibits tube formation of HUVEC and invasion of $D U-145$ cells in vitro. DU-145 prostate cancer cells express and secrete angiogenic factors for angiogenic process involving endothelial cells. To determine the anti-angiogenic activity of AGA, the conditioned medium of DU-145 cells treated with $100 \mu \mathrm{M}$ AGA was used to culture HUVEC on matrigel for $24 \mathrm{~h}$. These results showed that HUVEC grown in conditioned medium of AGA treated DU-145 cells were severely defective in tube formation on matrigel (Fig. 4A). However, the tube formation was not affected in the HUVEC when cultured in the control conditioned medium of DU-145 cells. We also tested the anti-invasive potential of AGA on DU-145 cells using matrigel coated transwell filters. These results also inferred that AGA treatment significantly prevented the number of DU-145 cells invading the transwell filters coated with matrigel compared to untreated cells (Fig. 4B).

AGA treatment down-regulates the expression of p65, VEGF and MMP-9 in DU-145 cells. NF- $\mathrm{BB}$ (p65) plays critical role in angiogenesis and invasion of prostate cancer cells by regulating the expression of key molecules, VEGF and matrix metalloproteinase-9 (MMP-9). Immunoblot analysis of DU-145 cells 

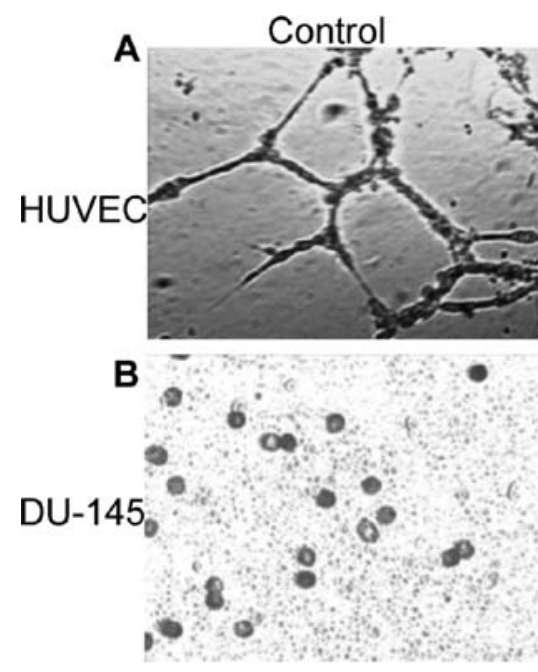
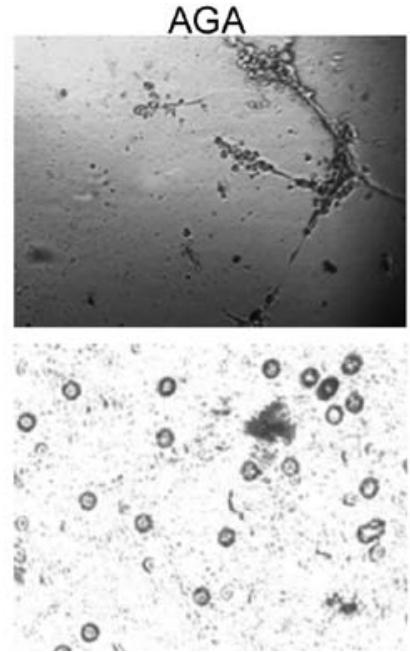

C

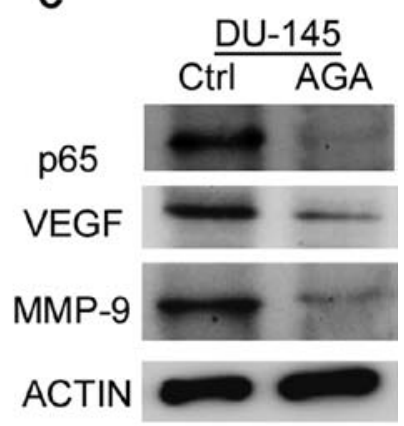

Figure 4. AGA prevents HUVEC tubulogenesis and DU-145 invasion by inhibiting NF- $\kappa$ B and its downstream regulated genes. (A) DU-145 cells were treated with AGA for $24 \mathrm{~h}$, washed and cultured subsequently with the conditioned medium for $24 \mathrm{~h}$. This condition medium was then used to culture HUVEC on matrigel coated in 96-well plates. Conditioned medium from untreated DU-145 cells served as controls. These results showed that AGA interferes in the tube formation of endothelial cells by targeting angiogenic factors expressed in DU-145 cells. (B) DU-145 cells were plated in presence or absence of AGA on matrigel pre-coated transwells for $24 \mathrm{~h}$. After $24 \mathrm{~h}$ of incubation, cells penetrated on the other side of the membrane were stained with HEMA and counted using a light microscope. Results showed that AGA inhibited the invasion of DU-145 cells on matrigel. (C) DU-145 cells treated with AGA for 24 h were used to determine the expression of p65, VEGF and MMP-9 by immunoblot analysis. The results showed that AGA robustly down-regulated the expression of these markers in DU-145 cells suggesting that AGA is a potential anti-angiogenic and anti-invasive agent against prostate cancer cells.

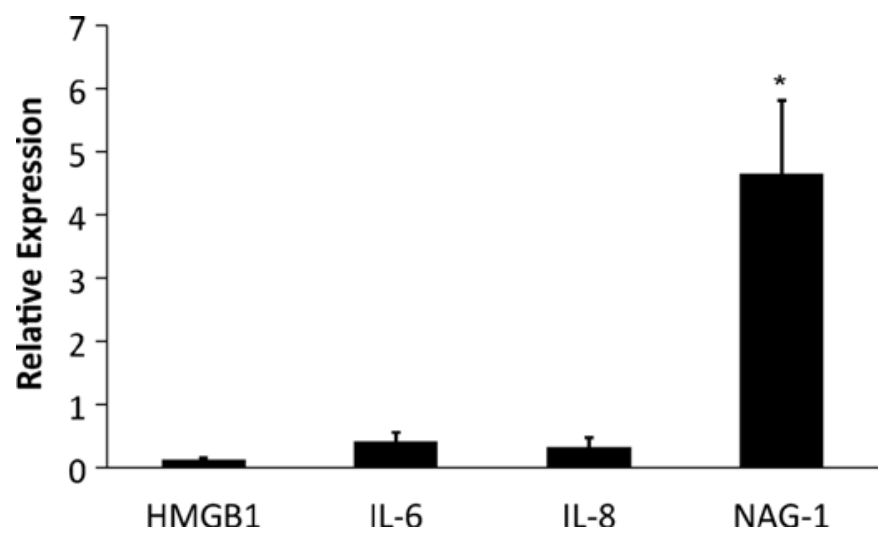

Figure 5. AGA inhibits the expression of inflammatory cytokine genes HMGB1, IL-6 and IL-8 and activates anti-inflammatory NAG-1 expression in DU-145 cells. DU-145 cells $\left(\sim 1 \times 10^{6}\right)$ were incubated with $100 \mu \mathrm{M}$ for $48 \mathrm{~h}$ at $37^{\circ} \mathrm{C}$ in $5 \% \mathrm{CO}_{2}$ environment. Untreated cells served as control. Following incubation, RNA was extracted and converted to cDNA. Expressions of HMGB1, IL-6, IL-8 and NAG-1 genes were then quantified by real-time PCR. Results presented are relative expression levels of genes in the treated samples compared to expression level of 1 in the untreated samples. Results show that AGA modulates the expression of inflammation related genes by down-regulating HMGB1, IL-6 and IL-8 expression and by up-regulating NAG-1 in DU-145 prostate cancer cells. Results presented are representative of one three similar experiments. "Statistically significant $(\mathrm{P}<0.05)$ compared to expression of HMGB1, IL-6 and IL-8.

treated with AGA showed a marked reduction in the expression of p65, VEGF and MMP-9 (Fig. 4C) underscoring its antiangiogenic and anti-invasive properties on DU-145 prostate cancer cells.

Effect of AGA on the expression of inflammatory genes. Several inflammatory-related genes have been linked with initiation and progression of prostate and other types of cancers $(29,30)$. Previous studies showed that inflammatory cytokines IL-6 and IL-8 are associated with augmented growth (31) and elevated metastatic potential (31-33). Similarly, over-expression of nuclear binding protein and proinflammatory mediator HMGB1 has been implicated in proliferation and metastasis of many cancer types, including prostate cancer (34). Hence, we studied the effect of AGA on inflammatory genes in DU-145 cells by quantitative real-time RT-PCR. Our results showed that AGA exerts a negative effect on expression of HMGB1, IL-6, and IL-8 while activating NAG-1 expression in DU-145 cells (Fig. 5).

\section{Discussion}

The number of men affected with prostate cancer is growing rapidly as the population of males over the age of 50 raises worldwide. Chronic inflammation caused by both hereditary and environmental factors has gained attention as a potential important element in the progression of cancer (35). Hence, in the present study we have tested the effects of a natural product AGA, an anti-inflammatory agent, on the androgen independent metastatic DU-145 prostate cancer cells.

Glycyrrhetinic acid was proven to inhibit the Epstein-Barr virus associated early antigen induction, ornithine decarboxylase and phospholipid metabolism controlled by tumor promoters (36-39). Further studies showed that glycyrrhetinic acid could also inhibit the tumor promoting activity of 12-O-tetradecanoylphorbol-13-acetate and teleocidin in mouse skin (36). Glycyrrhetinic acid has negative effect on growth and melanogenesis in cultured B16 melanoma cells and, 20 times lesser concentration of glycyrrhetinic acid than that of glycyrrhizin was needed to cause the same effect (40). Recently, we reported that glycyrrhizin could induce growth inhibition on prostate cancer cells (11). In the current study, our results show that AGA has potent anti-proliferative effects on both LNCaP and DU-145 prostate cancer cells. Interestingly, our 
results showed that androgen-independent DU-145 cells were more sensitive to AGA treatment compared to androgen dependent LNCaP cells suggesting AGA might have differential effects on the stage and type of prostate cancer cells.

Following androgen ablation treatment, androgen-dependent prostate cancer cells cease to proliferate and undergo apoptosis. However, due to the heterogeneous presence of androgenindependent cells evolved from androgen-dependent cells, these cells continue to proliferate and their proliferation rate exceeds the apoptosis rate (41). Hence, an effective chemotherapeutic agent should not only limit proliferation, but should be capable of activating programmed death of androgenindependent metastatic prostatic cancer cells. As exposure of AGA to DU-145 reduced the proliferation and growth of these androgen-independent metastatic prostate cancer cells, we have analyzed whether apoptosis is involved in the reduction of cell viability using fluorescent microscopy. Binding of Annexin V to AGA treated DU-145 cells confirmed the proapoptotic potential of AGA. Flow cytometric analysis of DU-145 cells treated with AGA also confirmed that AGA induces apoptosis. Previous studies showed that AGA can induce apoptosis in MCF-7 breast cancer cells (21). Similarly, glycyrrhetinic acid induced apoptosis in human hepatoma (HLE), promyelotic leukemia (HL-60) and stomach cancer (KATO III) cells in a dose- and time-dependent manner (42). Thus, our study reiterates the apoptotic potential of AGA against the viability of cancer cells. Angiogenesis and invasion process plays a key role in the establishment and distant metastases of prostate cancer cells $(43,44)$. Our preliminary results show that AGA has the ability to prevent both angiogenesis (tube formation of HUVEC) and invasion of DU-145 advanced prostate cancer cells mainly by targeting p65, VEGF and MMP-9 expression. Over-expression of p65, VEGF and MMP-9 is critical for the progression of prostate cancer. There-fore, AGA may be a promising anti-cancer agent which may be beneficial in the prevention and treatment of prostate cancer.

Recent studies showed that inflammation plays an important role in the initiation and progression of several kinds of cancers including prostate $(45,46)$. Inflammatory cells and several mediators of inflammation including cytokines and chemokines promote the microenvironment required for cancer development. The pro-inflammatory cytokine levels, such as IL-6 and IL-8, are elevated in serum of men with advanced hormone resistant disease compared to men with hormonesensitive prostate cancer (47-49). As inflammation and cell proliferation are associated with the development of prostate cancer, chemotherapeutic agents having anti-inflammatory as well as pro-apoptotic potential could be advantageous in cancer treatment. Previous studies showed that similar to that of glucocorticoid, AGA also has anti-inflammatory potential (22). Hence, we studied the effect of AGA over the production of proinflammatory mediators HMGB1, IL-6 and IL-8 in DU-145 cells.

Over-expression of HMGB1 is reported in prostate cancer cells $(50,51)$ and depletion of HMGB1 expression induces apoptosis in prostate cancer cells (52). HMGB1 is a potent attractant for inflammatory cells including neutrophils, monocytes and macrophages as well as inducer of pro-inflammatory cytokines such as TNF- $\alpha$, IL-1 $\alpha$, IL-1 $\beta$, IL-6 and IL- 8 production
$(53,54)$. Interestingly, HMGB1 is also an angiogenic switch molecule (55) and NF- $\kappa \mathrm{B}$ interacting molecule (56) thus possibly regulating the expression of VEGF in DU-145 cells. IL-6 acts as an autocrine and paracrine growth factor for androgen-independent prostate cancer cell lines and depletion of IL-6 rendered these cells sensitive to chemotherapeutic agents (57). IL-8, another important pro-inflammatory cytokine, modulates the growth and metastasis of androgen-independent prostate cancer cells and confers chemotherapeutic resistance to them (58). Our results showed that AGA could decrease the expression of HMGB1, IL- 6 and IL-8 in DU-145 cells. Interestingly, AGA activated the expression of NAG-1, an antiinflammatory and apoptosis related gene in DU-145 prostate cancer cells. Thus, AGA could target multiple mechanisms that promote prostate carcinogenesis and progression.

In conclusion, AGA, a glycyrrhizin metabolite, is able to suppress the proliferation of androgen-independent metastatic prostate carcinoma cell line DU-145 through the induction of apoptosis in a dose-dependent manner. In addition, our studies also showed that AGA inhibited the tube formation of endothelial cells and prevented the invasion of DU-145 cells in vitro. Besides, AGA could down-regulate the expression of inflammatory mediators HMGB1, IL-6 and IL-8. Further investigations are necessary to confirm the potential of AGA as a therapeutic agent against prostate cancer.

\section{Acknowledgements}

This study was supported in part by funding received from Excellence in Academic Medicine (EAM) award of Swedish American Health System and grant no. 141287 from the American Cancer Society, Illinois Division, Inc. awarded to M.G.

\section{References}

1. Jemal A, Siegel R, Xu J and Ward E: Cancer statistics, 2010. CA Cancer J Clin 60: 277-300, 2010.

2. Wang ZY and Nixon DW: Licorice and cancer. Nutr Cancer 39: $1-11,2001$.

3. Nomura T and Fukai T: Phenolic constituents of licorice (Glycyrrhiza species). Fortschr Chem Org Naturst 73: 1-158, 1998.

4. Mizutani K, Kuramoto T, Tamura Y, et al: Sweetness of glycyrrhetic acid 3-O-beta-D-monoglucuronide and the related glycosides. Biosci Biotechnol Biochem 58: 554-555, 1994.

5. Iida K, Uematsu Y, Suzuki K, Yasuno T, Hirata K and Ito K: [Properties of commercial licorice extracts used as a food additive]. Shokuhin Eiseigaku Zasshi 48: 112-117, 2007.

6. Carmines EL, Lemus R and Gaworski CL: Toxicologic evaluation of licorice extract as a cigarette ingredient. Food Chem Toxicol 43: 1303-1322, 2005.

7. Baltina LA: Chemical modification of glycyrrhizic acid as a route to new bioactive compounds for medicine. Curr Med Chem 10: 155-171, 2003.

8. Rackova L, Jancinova V, Petrikova M, et al: Mechanism of antiinflammatory action of liquorice extract and glycyrrhizin. Nat Prod Res 21: 1234-1241, 2007.

9. Takahara T, Watanabe A and Shiraki K: Effects of glycyrrhizin on hepatitis B surface antigen: a biochemical and morphological study. J Hepatol 21: 601-609, 1994.

10. He JX, Akao T, Nishino T and Tani T: The influence of commonly prescribed synthetic drugs for peptic ulcer on the pharmacokinetic fate of glycyrrhizin from Shaoyao-Gancao-tang. Biol Pharm Bull 24: 1395-1399, 2001

11. Thirugnanam S, Xu L, Ramaswamy $\mathrm{K}$ and Gnanasekar $\mathrm{M}$ : Glycyrrhizin induces apoptosis in prostate cancer cell lines DU-145 and LNCaP. Oncol Rep 20: 1387-1392, 2008. 
12. Niwa K, Lian Z, Onogi K, et al: Preventive effects of glycyrrhizin on estrogen-related endometrial carcinogenesis in mice. Oncol Rep 17: 617-622, 2007.

13. Harada S: The broad anti-viral agent glycyrrhizin directly modulates the fluidity of plasma membrane and HIV-1 envelope. Biochem J 392: 191-199, 2005.

14. Van Rossum TG, Vulto AG, De Man RA, Brouwer JT and Schalm SW: Review article: glycyrrhizin as a potential treatment for chronic hepatitis C. Aliment Pharmacol Ther 12: 199-205, 1998.

15. Cinatl J, Morgenstern B, Bauer G, Chandra P, Rabenau H and Doerr HW: Glycyrrhizin, an active component of liquorice roots, and replication of SARS-associated coronavirus. Lancet 361: 2045-2046, 2003.

16. Kim DH, Hong SW, Kim BT, Bae EA, Park HY and Han MJ: Biotransformation of glycyrrhizin by human intestinal bacteria and its relation to biological activities. Arch Pharm Res 23: $172-177,2000$

17. Ikeda T, Yokomizo K, Okawa M, et al: Anti-herpes virus type 1 activity of oleanane-type triterpenoids. Biol Pharm Bull 28: 1779-1781, 2005

18. Zeng CX, Yang Q and Hu Q: A comparison of the distribution of two glycyrrhizic acid epimers in rat tissues. Eur J Drug Metab Pharmacokinet 31: 253-258, 2006.

19. Ha YM, Cheung AP and Lim P: Chiral separation of glycyrrhetinic acid by high-performance liquid chromatography. J Pharm Biomed Anal 9: 805-809, 1991.

20. Chintharlapalli S, Papineni S, Jutooru I, McAlees A and Safe S Structure-dependent activity of glycyrrhetinic acid derivatives as peroxisome proliferator-activated receptor \{gamma\} agonists in colon cancer cells. Mol Cancer Ther 6: 1588-1598, 2007.

21. Rossi T, Castelli M, Zandomeneghi G, et al: Selectivity of action of glycyrrhizin derivatives on the growth of MCF-7 and HEP-2 cells. Anticancer Res 23: 3813-3818, 2003.

22. Amagaya S, Sugishita E, Ogihara Y, Ogawa S, Okada K and Aizawa T: Comparative studies of the stereoisomers of glycyrrhetinic acid on anti-inflammatory activities. J Pharmacobiodyn 7: 923-928, 1984.

23. Sugishita E, Amagaya S and Ogihara Y: Structure-activity studies of some oleanane triterpenoid glycosides and their related compounds from the leaves of Tetrapanax papyriferum on antiinflammatory activities. J Pharmacobiodyn 5: 379-387, 1982.

24. Wang ZY, Agarwal R, Zhou ZC, Bickers DR and Mukhtar H: Inhibition of mutagenicity in Salmonella typhimurium and skin tumor initiating and tumor promoting activities in SENCAR mice by glycyrrhetinic acid: comparison of 18 alpha- and 18 beta-stereoisomers. Carcinogenesis 12: 187-192, 1991.

25. Darzynkiewicz Z, Sharpless T, Staiano-Coico L and Melamed MR: Subcompartments of the G1 phase of cell cycle detected by flow cytometry. Proc Natl Acad Sci USA 77: 6696-6699, 1980.

26. Newman SP, Foster PA, Stengel C, et al: STX140 is efficacious in vitro and in vivo in taxane-resistant breast carcinoma cells. Clin Cancer Res 14: 597-606, 2008.

27. Kureishi Y, Luo Z, Shiojima I, et al: The HMG-CoA reductase inhibitor simvastatin activates the protein kinase Akt and promotes angiogenesis in normocholesterolemic animals. Nat Med 6: 1004-1010, 2000.

28. Zhang $\mathrm{H}$, Morisaki T, Matsunaga $\mathrm{H}$, et al: Protein-bound polysaccharide PSK inhibits tumor invasiveness by down-regulation of TGF-beta1 and MMPs. Clin Exp Metastasis 18: 343-352, 2000.

29. Mantovani A, Allavena P, Sica A and Balkwill F: Cancer-related inflammation. Nature 454: 436-444, 2008.

30. Hold GL and El-Omar EM: Genetic aspects of inflammation and cancer. Biochem J 410: 225-235, 2008.

31. Smith CW, Chen Z, Dong G, et al: The host environment promotes the development of primary and metastatic squamous cell carcinomas that constitutively express proinflammatory cytokines IL-1alpha, IL-6, GM-CSF, and KC. Clin Exp Metastasis 16: $655-664,1998$

32. Ueda T, Shimada E and Urakawa T: Serum levels of cytokines in patients with colorectal cancer: possible involvement of interleukin-6 and interleukin-8 in hematogenous metastasis. J Gastroenterol 29: 423-429, 1994.

33. Singh RK, Gutman M, Radinsky R, Bucana CD and Fidler IJ: Expression of interleukin 8 correlates with the metastatic potential of human melanoma cells in nude mice. Cancer Res 54: 3242-3247, 1994.

34. Ellerman JE, Brown CK, De Vera M, et al: Masquerader: high mobility group box-1 and cancer. Clin Cancer Res 13: 2836-2848, 2007.
35. De Marzo AM, Platz EA, Sutcliffe S, et al: Inflammation in prostate carcinogenesis. Nat Rev Cancer 7: 256-269, 2007.

36. Nishino H, Kitagawa K and Iwashima A: Antitumor-promoting activity of glycyrrhetic acid in mouse skin tumor formation induced by 7,12-dimethylbenz[a]anthracene plus teleocidin. Carcinogenesis 5: 1529-1530, 1984.

37. Okamoto H, Yoshida D and Mizusaki S: Inhibition of 12-O-tetradecanoylphorbol-13-acetate-induced induction in Epstein-Barr virus early antigen in Raji cells. Cancer Lett 19: 47-53, 1983.

38. Okamoto H, Yoshida D, Saito Y and Mizusaki S: Inhibition of 12-O-tetradecanoylphorbol-13-acetate-induced ornithine decarboxylase activity in mouse epidermis by sweetening agents and related compounds. Cancer Lett 21: 29-35, 1983.

39. Saito Y, Okamoto H, Mizusaki S and Yoshida D: Inhibition of 12-O-tetradecanoylphorbol-13-acetate-induced induction of Epstein-Barr virus early antigen in Raji cells by some inhibitors of tumor promotion. Cancer Lett 32: 137-144, 1986.

40. Abe H, Ohya N, Yamamoto KF, Shibuya T, Arichi S and Odashima S: Effects of glycyrrhizin and glycyrrhetinic acid on growth and melanogenesis in cultured B16 melanoma cells. Eur J Cancer Clin Oncol 23: 1549-1555, 1987.

41. Isaacs JT: Hormonally responsive versus unresponsive progression of prostatic cancer to antiandrogen therapy as studied with the Dunning R-3327-AT and -G rat adenocarcinomas. Cancer Res 42: 5010-5014, 1982.

42. Hibasami H, Iwase H, Yoshioka K and Takahashi H: Glycyrrhetic acid (a metabolic substance and aglycon of glycyrrhizin) induces apoptosis in human hepatoma, promyelotic leukemia and stomach cancer cells. Int J Mol Med 17: 215-219, 2006.

43. Weidner N, Carroll PR, Flax J, Blumenfeld W and Folkman J: Tumor angiogenesis correlates with metastasis in invasive prostate carcinoma. Am J Pathol 143: 401-409, 1993.

44. Wakui S, Furusato M, Itoh T, et al: Tumour angiogenesis in prostatic carcinoma with and without bone marrow metastasis: a morphometric study. J Pathol 168: 257-262, 1992.

45. Lu H, Ouyang $\mathrm{W}$ and Huang $\mathrm{C}$ : Inflammation, a key event in cancer development. Mol Cancer Res 4: 221-233, 2006.

46. Coussens LM and Werb Z: Inflammation and cancer. Nature 420: 860-867, 2002.

47. Veltri RW, Miller MC, Zhao G, et al: Interleukin- 8 serum levels in patients with benign prostatic hyperplasia and prostate cancer. Urology 53: 139-147, 1999.

48. Pfitzenmaier J, Vessella R, Higano CS, Noteboom JL, Wallace D Jr and Corey E: Elevation of cytokine levels in cachectic patients with prostate carcinoma. Cancer 97: 1211-1216, 2003.

49. Uehara H, Troncoso P, Johnston D, et al: Expression of interleukin-8 gene in radical prostatectomy specimens is associated with advanced pathologic stage. Prostate 64: 40-49, 2005.

50. Kuniyasu H, Chihara Y, Kondo H, Ohmori H and Ukai R: Amphoterin induction in prostatic stromal cells by androgen deprivation is associated with metastatic prostate cancer. Oncol Rep 10: 1863-1868, 2003.

51. Ishiguro H, Nakaigawa N, Miyoshi Y, Fujinami K, Kubota Y and Uemura $\mathrm{H}$ : Receptor for advanced glycation end products (RAGE) and its ligand, amphoterin are overexpressed and associated with prostate cancer development. Prostate 64: 92-100, 2005.

52. Gnanasekar M, Thirugnanam S and Ramaswamy K: Short hairpin RNA (shRNA) constructs targeting high mobility group box-1 (HMGB1) expression leads to inhibition of prostate cancer cell survival and apoptosis. Int J Oncol 34: 425-431, 2009.

53. Erlandsson Harris $\mathrm{H}$ and Andersson U: Mini-review: the nuclear protein HMGB1 as a proinflammatory mediator. Eur J Immunol 34: 1503-1512, 2004.

54. Andersson U, Wang H, Palmblad K, et al: High mobility group 1 protein (HMG-1) stimulates proinflammatory cytokine synthesis in human monocytes. J Exp Med 192: 565-570, 2000.

55. Schlueter C, Weber H, Meyer B, et al: Angiogenetic signaling through hypoxia: HMGB1: an angiogenetic switch molecule. Am J Pathol 166: 1259-1263, 2005.

56. Agresti A, Lupo R, Bianchi ME and Muller S: HMGB1 interacts differentially with members of the Rel family of transcription factors. Biochem Biophys Res Commun 302: 421-426, 2003.

57. Culig Z, Steiner H, Bartsch $G$ and Hobisch A: Interleukin-6 regulation of prostate cancer cell growth. J Cell Biochem 95: 497-505, 2005.

58. Araki S, Omori Y, Lyn D, et al: Interleukin-8 is a molecular determinant of androgen independence and progression in prostate cancer. Cancer Res 67: 6854-6862, 2007. 